\title{
Перспективы применения шунгита как сорбента формальдегида в композитных материалах
}

\author{
(C) 2021 Петухова Г.А., Кулькова Т.А. \\ Институт физической химии и электрохимии им. А.Н. Фрумкина РАН, Москва
}

Поступила в редакцию 9.10.2020 г.

DOI: $10.17308 /$ sorpchrom.2021.21/3225

При производстве современных конструкционных материалов на основе древесины используют синтетические клеи, токсичность которых определяется наличием свободного формальдегида. Выделение свободного формальдегида из изделий может продолжаться в течение продолжительного неопределенного периода. Разработка способов снижения эмиссии формальдегида в технологии получения и при эксплуатации композиционных древесных материалов, несомненно, актуальная задача. Цель исследования: оптимизация способа повышения адсорбционно-структурных характеристик наполнителя на основе природного шунгита, исследование влияния пористой структуры углеродсодержащих адсорбентов, используемых в качестве наполнителей, на эмиссию формальдегида в древесных клееных композиционных материалах. Как наполнители исследованы шунгит, активированный уголь БАУ-7, нанодиспергированный углеродный материал Сибунит и сажа ПМ-75. Для развития пористой структуры и повышения дисперсности шунгита применялись следующие методы модифицирования шунгита: механоактивация сухим способом, активация электромагнитными полями в диапазоне $150 \div 800 \mathrm{~W}$ СВЧ (ЭМП СВЧ), парогазовое активирование в различных температурных и временных режимах и химическое активирование серной кислотой. Химическое активирование проводили в растворе $2 \mathrm{M} \mathrm{H}_{2} \mathrm{SO}_{4}$ при постоянном перемешивании при температуре $97^{\circ} \mathrm{C}$ в течение 7.5 часов с помощью ротационного испарителя Heidolph LABOROTA 4000. Анализ текстуры и состояния поверхности материалов проводили методами равновесной адсорбции, колебательной спектроскопии, рентгеновского микроанализа (метод EDAX). Эмиссия свободного формальдегида изучалась камерным методом. Показано, что механоактивация и термоактивирование позволяют увеличить поверхность шунгита в 1035 раз и получить образцы с высокой дисперсностью (в интервале от 90 до 40 мкм). Наиболее эффективным в качестве адсорбционного наполнителя клеевой композиции оказалось применение нанодиспергированного механоактивированного шунгита и Сибунита. Применение нанодиспергированного механоактивированного шунгита позволяет снизить эмиссию формальдегида из древесных композитных материалов до $0.040 \mathrm{Mг} / \mathrm{M}^{3}$, что в два раза ниже нормы 0.124 мг/м³ формальдегида в воздухе.

Ключевые слова: углеродсодержащие сорбенты, шунгит, пористая структура, адсорбция, формальдегид.

\section{Введение}

В настоящее время области применения органических веществ в технологиях производства композиционных материалов достаточно разнообразны. Неуклонно растет производство и применение конструкционных материалов на основе древесины, таких как фанера, древесностружечные (ДСтП) и древесново- локнистые (ДВП) плиты. При их изготовлении используют современные синтетические клеи, токсичность которых определяется наличием свободного формальдегида, содержание которого повышается в результате термической и гидролитической неустойчивости используемой смолы. Выделение свободного формальдегида из изделий может продолжаться в течение продолжительного неопределен- 
ного периода. Экономическая и экологическая эффективность конструкционных древесных клееных материалов определяется рядом показателей, таких как расходный объем основных компонентов клея, прочность получаемого композитного материала, экономичность технологического процесса получения материала. Однако наиболее значимым показателем является токсичность клеевой композиции. Поэтому разработка способов снижения эмиссии формальдегида в технологии получения и при эксплуатации композиционных строительных древесных материалов, несомненно, актуальна, так как позволяет решать экологические проблемы безопасности. Известны работы по модифицированию карбамидоформальдегидных смол различными добавками для снижения эмиссии формальдегида: солями органических кислот, лигносульфатом и патокой, введением кремнезема [1-5]. В ряде работ предлагается использовать алюминий содержащий, фосфатный модификаторы [6]. Известны работы, описывающие особенности модифицирования клеев с целью снижения токсичности древесных материалов шунгитовыми сорбентами [7, 8]. В тоже время применение сорбционных технологий, сорбентов в настоящее время для решения проблемы снижения эмиссии токсичных веществ из композитных материалов используется недостаточно. Углеродсодержащие материалы и активированные угли обладают рядом существенных преимуществ для применения в качестве наполнителя древесно-клееных композитных строительных материалов.
Они являются универсальными адсорбентами с развитой пористостью, что позволяет им адсорбировать широкий круг токсичных веществ с различными физико-химическими свойствами, включая формальдегид, характеризуются гидрофобностью, термостойкостью, недороги, не требуют регенерации, сохраняют прочность независимо от фракционного состава.

Цель настоящей работы: оптимизация способа повышения адсорбционноструктурных характеристик наполнителя на основе природного шунгита, исследование влияния пористой структуры углеродсодержащих адсорбентов, используемых в качестве наполнителей, на эмиссию формальдегида в древесных клееных композиционных материалах.

\section{Экспериментальная часть}

Объекты исследования. В качестве адсорбционных наполнителей были рассмотрены углеродсодержащие адсорбционные материалы с различной пористостью: микропористый активированный уголь БАУ-7, мезопористый наноструктурированный углеродный материал Сибунит, непористый технических углерод (сажа) марки ПМ-75 и шунгит-III Зажогинского месторождения (Карелия). Параметры пористой структуры адсорбционных материалов представлены в табл. 1.

Для получения древесно-клееной композиции использовался шпон березы, карбамидоформальдегидный клей KRONORES марки KBU 1000-1800 с классом эмиссии по формальдегиду E1

Таблица 1. Параметры пористой структуры адсорбентов

Table 1. Parameters of the porous structure of adsorbents

\begin{tabular}{|c|c|c|c|c|}
\hline Образец & $\begin{array}{l}\text { Объем микро- } \\
\text { пор } \mathrm{W}_{0}, \mathrm{~cm}^{3} / \Gamma\end{array}$ & $\begin{array}{l}\text { Ширина мик- } \\
\text { ропор Н, нм }\end{array}$ & $\begin{array}{c}\text { Объем мезопор } \\
\mathrm{V}_{\mathrm{me}}, \mathrm{cm}^{3} / \Gamma\end{array}$ & $\begin{array}{c}\text { Удельная по- } \\
\text { верхность } \\
\mathrm{S}_{\text {Бэт, }}{ }^{2} / \Gamma\end{array}$ \\
\hline Шунгит & 0.03 & 20.50 & 0.06 & 2 \\
\hline БАУ-7 & 0.23 & 1.12 & 0.10 & $50 *$ \\
\hline Сибунит & - & - & 0.72 & 300 \\
\hline ПМ-75 & - & - & - & 75 \\
\hline
\end{tabular}

"для образца микропористого активированного угля приведена удельная поверхность мезопор

*for a sample of microporous activated carbon, the specific surface of mesopores is given. 
( $\mathrm{pH}=7.2-8.7$; плотность $=1270-1300 \mathrm{~kg} / \mathrm{m}^{3}$; растворимость в воде: $1: 1$; вязкость 300-1000 мПа с $/ 20^{\circ} \mathrm{C}$; содержание свободного формальдегида $0.2 \%$; массовая доля сухого остатка в рабочем растворе $\mathrm{min}$ 65\%), кислотный отвердитель в виде комбинации раствора нитрата аммония $\left(\mathrm{NH}_{4} \mathrm{NO}_{3}\right)$ с концентрацией $60 \%$ и муравьиной кислоты с концентрацией 1-2\%, что обеспечивало среду со значением $\mathrm{pH}=4$.

Дисперсность адсорбционных наполнителей. Для повышения дисперсности исходный шунгит подвергался последовательному размолу. Измельчение исследуемых образцов шунгита до порошкообразного состояния при помощи вибромеханического размола на вибромельнице MTAKUTESZ (Венгрия) и при помощи планетарной шаровой мономельницы серии PULVERISETTE 6 (Fritsch, Германия) позволило получить микрогранулы с размером частиц менее 40 мкм. Далее, серия образцов подвергались измельчению в бисерном диспергаторе DYNO-MILL (Multi Lab, Испания) по технологии мокрого размола с гранулами циркония в дисперсной жидкой среде под воздействием механических сил при скорости 700 об/мин., температуре $40^{\circ} \mathrm{C}$ и ультразвуковом диспергаторе Ultrasonic Homogenizers (Hielscher Ultrasonics, Германия). На рис. 1 представлено распреде- ление частиц шунгита по размерам в результате его измельчения по технологии мокрого помола и диспергирования в виде суспензии в $0.1 \%$-ном растворе олеиновой кислоты в воде. Как видно из рисунка, данная методика позволила получить образцы высокодиспергированного шунгита с преобладающим радиусом частиц 100 нм.

Для повышения эффективности сорбентов целесообразно фракционирование частиц, вводимых в клеевую композицию адсорбционных наполнителей. Это важно и для обеспечения технологических требований, предъявляемых к толщине слоя клея (1 мм) при склеивании фанеры. Фракции шунгита были получены с помощью вибрационного просеивателя FRITSCH просеиванием сухих образцов сквозь систему сит с постоянным встряхиванием. Дисперсность порошков определялась методом динамического светорассеяния на приборе Zetasizer Nano S.

Модифицирование шунгита. Исходный образец шунгита представляет собой материал практически неразвитой пористой структурой, удельной поверхностью $2 \mathrm{~m}^{2} / \Gamma$, низкой дисперсностью. Для повышения его адсорбционной способности целесообразно модифицирование пористой структуры. Возможности его физического и химического модифицирования во многом определяются сложным

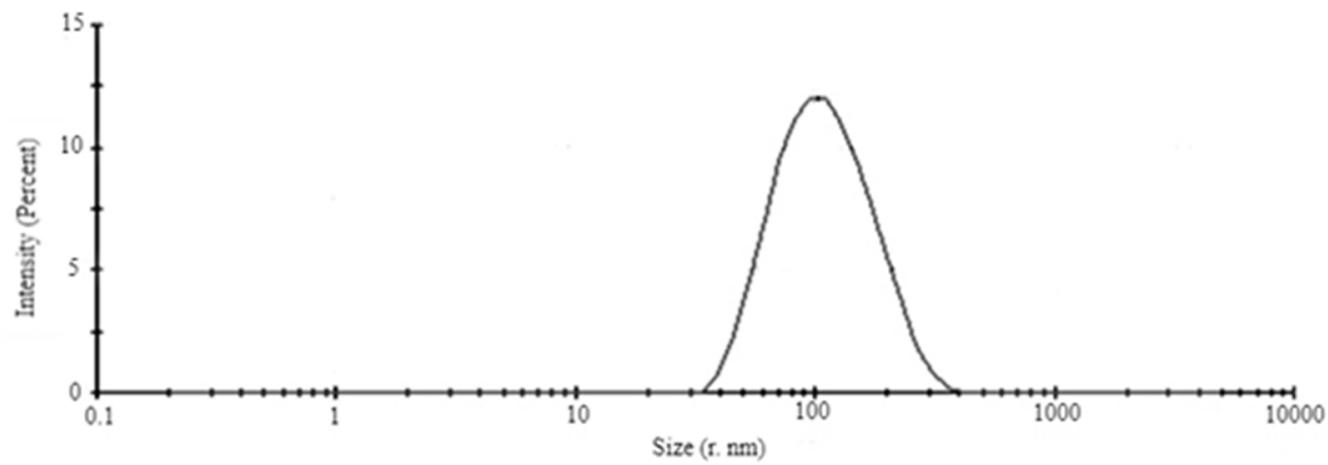

Рис. 1. Распределение частиц шунгита по размеру для образца, измельченного по технологии мокрого помола и диспергированного в виде суспензии в $0.1 \%$-ном растворе олеиновой кислоты в воде

Fig. 1. The distribution of schungite particles by size for a sample ground by wet grinding technology and dispersed in the form of a suspension in a $0.1 \%$ solution of oleic acid in water 
Таблица 2. Параметры пористой структуры модифицированных образцов шунгита Table 2. Parameters of the porous structure of modified samples of schungite

\begin{tabular}{|c|c|c|}
\hline Метод модифицирования & $\begin{array}{c}\text { Фракционный } \\
\text { состав, мкм }\end{array}$ & $\begin{array}{c}\text { Удельная поверхность } \boldsymbol{S}_{\boldsymbol{b}} \boldsymbol{\text { д }}, \\
\mathrm{M}^{2} / \Gamma\end{array}$ \\
\hline Термоактивация & & 28 \\
$410^{\circ} \mathrm{C}$ & $\leq 40$ & 30 \\
$530^{\circ} \mathrm{C}$ & $40 \div 50$ & 9 \\
$750^{\circ} \mathrm{C}$ & $50 \div 60$ & 70 \\
\hline Механоактивация & $\leq 40$ & 26 \\
\hline Химическое модифицирование в рас- & $\leq 40$ & 21 \\
творе $2 \mathrm{M} \mathrm{H}_{2} \mathrm{SO}_{4}$ & & \\
\hline Активация в ЭМП СВЧ & $\leq 40$ & \\
\hline
\end{tabular}

химическим состоянием его поверхности: наличие на ней широкого спектра кислородосодержащих гидрофильногидрофобных комплексов [9-12]. Однако из-за сложной морфологии включения углерода в силикатную матрицу шунгита, механические или флотационные методы практически не позволяют достигнуть обуглероживания материала. В работе применялись следующие методы модифицирования шунгита: механоактивация сухим способом, активация электромагнитными полями в диапазоне $150 \div 800 \mathrm{~W}$ СВЧ (ЭМП СВЧ), парогазовое активирование в различных температурных и временных режимах и химическое активирование серной кислотой. Химическое активирование проводили в растворе $2 \mathrm{M}$ $\mathrm{H}_{2} \mathrm{SO}_{4}$ при постоянном перемешивании при температуре $97^{\circ} \mathrm{C}$ в течение 7.5 часов с помощью ротационного испарителя Heidolph LABOROTA 4000.

Текстурные характеристики и состав образцов адсорбционных наполнителей. Исследование текстурных характеристик, включающих структурно-геометрические параметры удельной поверхности и пористой структуры исходного и модифицированных образцов шунгита, а также углеродных сорбентов БАУ, Сибунит и ПМ-75 проводили адсорбционными методами по адсорбции паров бензола и низкотемпературной адсорбции азота. Изотермы адсорбции/десорбции паров бензола определялись при температуре 293 К весовым методом на высоковакуумной сорбционной установке с пружин- ными кварцевыми микровесами с чувствительностью около 20 мкг при нагрузке до 0.2 г. Перед измерениями образцы предварительно вакуумировали до постоянного веса при остаточном давлении $10^{-5}$ Па и температуре $200^{\circ} \mathrm{C}$. Для оценки параметров микропористой структуры применялся современный математический аппарат Теории объемного заполнения микропор, уравнение Дубинина-Радушкевича (ДР) [13-15].

Удельную поверхность образцов $\left(S_{\text {Бэт) }}\right)$ измеряли по адсорбции азота объемным статическим методом при $-196^{\circ} \mathrm{C}$ в диапазоне равновесных относительных давлений азота от 0.05 до 0.99 с использованием автоматического анализатора Tri Star II 3020. Предварительная дегазация образцов проводилась вакуумной станцией Vac Prep 3000 (Micromeritics Instrument Corp., США). Параметры пористой структуры модифицированных образцов шунгита представлены в табл. 2 .

Качественные изменения структуры поверхности шунгита в результате модифицирования исследовали методом колебательной спектроскопии [16]. Химический элементный состав поверхности модифицированных образцов шунгита исследовали методом рентгеновского микроанализа (метод EDAX).

Формирование образцов древесных клееных композиционных материалов. Клеевую композицию получали, добавляя отвердитель в массу карбамидоформальдегидного клея с перемешиванием в течение 1-2 минут. В предварительно выдержанный при 


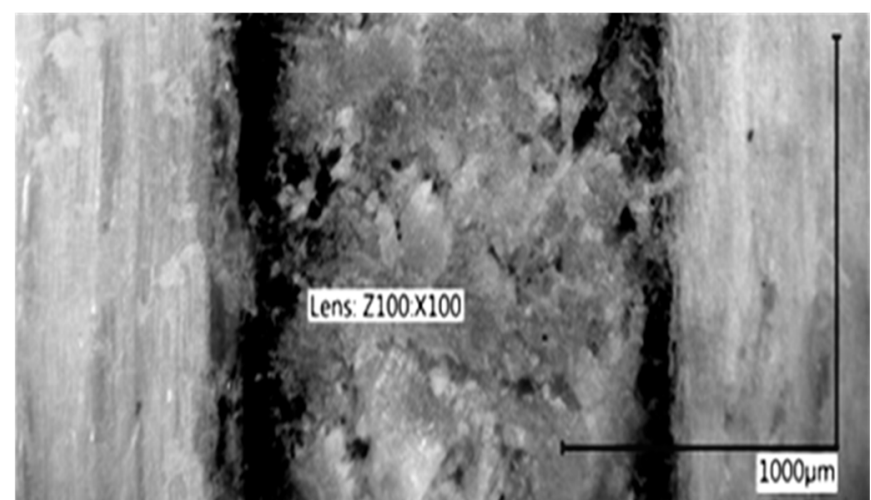

Рис. 2. Образец трехслойной фанеры с наполнителем (шунгит, модифицированный парогазовой активацией при $530^{\circ} \mathrm{C}$ ) в клеевых слоях. Снимок получен с помощью цифрового 3D микроскопа серии Wide-Area 3D Measurement System VR-3000 Series

Fig. 2. A sample of three-layer plywood with a filler (schungite modified by steam-gas activation at $530^{\circ} \mathrm{C}$ ) in adhesive layers. Image was taken using a Wide-Area 3D Measurement System VR-3000 Series digital 3D microscope

комнатной температуре клей добавляли комбинацию отвердителей, а затем вводили модификаторы (адсорбционные наполнители) в массовой доле 5, 10 и $15 \%$. Смесь перемешивали еще в течение 5 минут до получения однородной консистенции.

Далее на лист шпона наносили рассчитанное, исходя из размеров фанеры (15.75 г на один слой фанеры), количество клеевой смеси и равномерно распределяли по всему объему. Листы шпона укладывали так, чтобы волокна древесины одного слоя были перпендикулярны предыдущему слою для сохранения прочности. Таким способом получали 3-х или 5-ти-слойные фанеры, которые далее помещали под пресс. Полученный материал направляли на горячее прессование при температуре $105^{\circ} \mathrm{C}$. Для твердой породы древесины (в данном случае береза) уста-

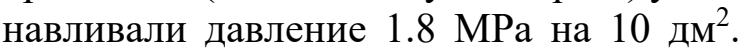
Выбор значения давления обусловлен тем, что при большем давлении может образовываться тонкий клеевой шов, при недостаточном давлении образуются пористые и непрочные соединения неравномерной толщины. Время прессования определяется из расчета: один слой клея толщиной 0.1 мм выдерживается в течение 1 минуты, и дополнительно, в течение еще 3-х минут. Трёхслойные фанеры спрессовывали, соответственно, в тече- ние 5 мин, пятислойные в течение 6 минут. Полученную фанеру направляли на сушильную подставку для завершения процесса отверждения в течение еще 7 суток. На рис. 2 представлена микрофотография образца трехслойной фанеры с наполнителем (шунгит, модифицированный парогазовой активацией при $530^{\circ} \mathrm{C}$ ) в клеевом слое.

Изучение эмиссии формальдегида из древесно-клееных композиций с адсорбционными наполнителями. Для определения содержания свободного формальдегида в отвержденной клееной композиции на основе карбамидоформальдегидного клея был использован «камерный метод». Метод позволяет измерить эмиссию формальдегида в контролируемом воздушном потоке, близком к типичным условиям окружающей среды в специально оборудованной камере (рис.3). Исследования проводились в Техническом Университете г. Зволена, Словакия.

Объем используемой камеры составляет $1 \mathrm{~m}^{3}$. Образцы помещаются внутрь камеры, куда подается чистый воздух с постоянным расходом. Расход воздуха определяется нормативами воздухообмена в жилом помещении. Воздушные насосы создают в камере небольшое избыточное давление для предотвращения проникновения атмосферного воздуха извне. Температура, 


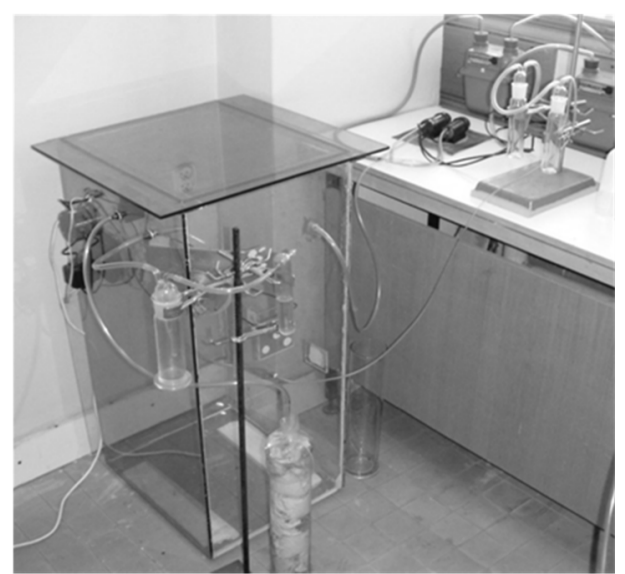

Рис. 3. Измерение эмиссии формальдегида из древесно-клееных композитных материалов камерным методом

Fig. 3. Measurement of formaldehyde emission from wood-glued composite materials by the chamber method

относительная влажность и интенсивность циркуляции воздушного потока контролируются и поддерживаются постоянными в течение всего времени испытаний. Завершение тестирования с получением значения эмиссии формальдегида происходит после достижения равновесного состояния, то есть стабилизации выделения формальдегида из образца. Накопленный банк данных показывает, что для достижения равновесного состояния требуется значительное время, от 10 дней до месяца. В процессе испытаний устанавливаются периодичность и места забора проб воздуха, а также их объем (от 30 до 120 дм $^{3}$ ). Формальдегид выделяется из отвержденной смолы в атмосферный воздух, который пропускается из герметичной системы в дистиллированную воду. Метод соответствует методике Европейской нормы EN 7171[17], которая применена в качестве стандарта по измерению эмиссии формальдегида из древесно-клееных композитных материалов. Концентрация формальдегида определялась ацетилацетоновым методом с использованием спектрофотометра, измеряющего поглощение световых волн длиной 412 нм. В течение месяца (иногда двух), как правило, накапливается достаточный объем данных, чтобы делать вывод о достижении установившегося значения эмиссии формальдегида.

\section{Обсуждение результатов}

Эмиссия формальдегида в древесноклееных композитных материалах во многом зависит от адсорбционной активности вводимых наполнителей и их дисперсности. Активный уголь БАУ-7, Сибунит обладают высокой сорбционной активностью, обязанной их развитой микро- и мезопористой структурам, значительно превосходящей адсорбционные возможности шунгита. Однако, как наиболее дешевый продукт, шунгит может служить хорошей альтернативой. Шунгитовые породы Карелии имеют силикатную основу и отличаются высокой термической стойкостью и механической прочностью. Обладая сложным минеральным составом (кварц, алюмосиликаты, углерод), они представляют интерес, как комплексный сорбент, сочетающий одновременно свойства углеродных и силикатных материалов. Как видно из табл.2, из примененных в исследовании методов развития его пористой структуры и повышения дисперсности, наиболее перспективными являются механоактивация и парогазовое активирование. В этих случаях наблюдается существенное развитие удельной поверхности (при механо- 
Таблица 3. Химический состав исходного и модифицированных образцов шунгита Table 3. Chemical composition of the original and modified samples of schungite

\begin{tabular}{|c|c|c|c|c|c|}
\hline $\begin{array}{c}\text { Образец } \\
\text { шунгита, } \\
\text { темпера- } \\
\text { тура обра- } \\
\text { ботки }\end{array}$ & $\begin{array}{c}\text { Удельная по- } \\
\text { верхность, } \\
\mathbf{m}^{2} / \Gamma\end{array}$ & $\mathrm{C}$ & $\mathrm{Si}_{2} \mathrm{O}_{3}$ & $\mathrm{Al}_{2} \mathrm{O}_{3}$ & $\mathrm{Fe}_{2} \mathrm{O}_{3}$ \\
\hline исходный & 2 & 31.00 & 54.50 & 4.62 & \\
\hline $410^{\circ} \mathrm{C}$ & 28 & 28.10 & 59.10 & 4.86 & 0.04 \\
\hline $530^{\circ} \mathrm{C}$ & 30 & 21.86 & 64.81 & 5.00 & 0.79 \\
\hline $750^{\circ} \mathrm{C}$ & 9 & 9.12 & 77.35 & 6.74 & 1.84 \\
\hline
\end{tabular}

активации - до $70 \mathrm{~m}^{2} / \Gamma$, при термоактивировании - до $\left.30 \mathrm{~m}^{2} / \Gamma\right)$.

Сравнение данных анализа элементного состава образцов шунгита и изменений пористой структуры при варьировании температурного активирования, приведенных в таблице 3, показывает, что повышение температуры активирования сопровождается уменьшением содержания углерода, соответствующим увеличением относительного содержания оксида кремния в образцах. Очевидно, что при этом происходит диффузия оставшегося углерода из объема в приповерхностные слои и на поверхность зерен сорбента, образование пор, что выражается в увеличении поверхности сорбента при температуре до $530^{\circ} \mathrm{C}$. Дальнейшее повышение температуры обработки до $750^{\circ} \mathrm{C}$ приводит к активному выгоранию углеродной составляющей, практически полной десорбции паров воды, сильной деформации (сжатию) силикатного каркаса и, как следствие, резкому уменьшению величины удельной поверхности.
Из представленных в таблице 4 результатов EDAX анализа элементного состава образцов исходного шунгита и нанодиспергированного до среднего размера частиц около 100 нм (рис. 1) следует, что диспергирование способствует обуглероживанию исходного образца и вызывает разрушение силикатной основы, при этом практически сохраняется сложный минеральный состав.

Спектральный анализ шунгита подтверждает структурные изменения, происходящие в процессе модифицирования этой сложной многофазной системы. На рис. 4 приведены спектры комбинационного рассеяния для исходного шунгита (1), термоактивированного при температуре $528{ }^{\circ} \mathrm{C}(2)$ и механоактивированного образца (3).

Наблюдаемые в спектрах линии, характерны для углеродных материалов: линия в области $\sim 1200 \mathrm{~cm}^{-1}$ (Т-линия), $\sim 1640 \mathrm{~cm}^{-1}$ (D-линия), $\sim 1560 \mathrm{~cm}^{-1}$ (G-линия), $\sim 1600 \mathrm{~cm}^{-1}$ ( $\mathrm{D}^{\prime}$-линия) [18]. Отношение $\mathrm{ID}_{\mathrm{D}} / \mathrm{I}_{\mathrm{G}}$ может служить показателем

Таблица 4. Элементный состав исходного и нанодиспергированногошунгита

Table 4. Elemental composition of the initial and nanodispersed schungite

\begin{tabular}{|c|c|c|}
\hline \multirow{2}{*}{ Элемент } & \multicolumn{2}{|c|}{ Концентрация, \% масс. } \\
\cline { 2 - 3 } & Исходный образец шунгита & Диспергированный образец шунгита \\
\hline $\mathrm{C}$ & 39.5 & 76.5 \\
\hline $\mathrm{Si}$ & 23.4 & 3.3 \\
\hline $\mathrm{O}$ & 25.1 & 11.7 \\
\hline $\mathrm{Al}$ & 1.2 & 1.2 \\
\hline $\mathrm{Fe}$ & 0.8 & 0.8 \\
\hline $\mathrm{Ca}$ & 0.3 & 0.4 \\
\hline $\mathrm{S}$ & 0.6 & 0.6 \\
\hline
\end{tabular}




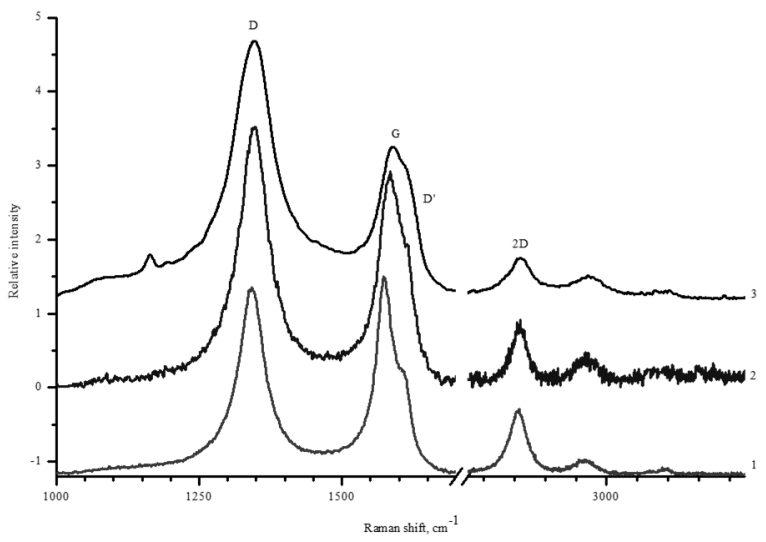

Рис. 4. Спектры комбинационного рассеяния образцов шунгита: 1 - исходный, 2 - механоактивированный, 3 - термоактивированный

Fig: 4. Raman spectra of schungite samples: 1 - original, 2 - mechanically activated, 3 - thermally activated

степени разупорядоченности структуры материала. Рост отношения D к G для модифицированных образцов шунгита по сравнению с этим показателем для исходного образца, свидетельствует об увеличении степени разупорядоченности в процессах механоактивации и термической активации. При температурной обработке, кроме изменения отношения $\mathrm{ID} / \mathrm{I}_{\mathrm{G}}$, наблюдается изменение полуширин D- и G- линий. Такой эффект объясняется началом разрушения структуры шунгита при термообработке, тогда как при механохимической активации не происходит разрушения внутренней структуры образца шунгита. Механоактивация, как способ модифицирования, позволяет достичь устойчиво стабильных размеров мелкодисперсного материала и обеспечить измельчение его частиц до размеров от 90 нм до 40 мкм, а также увеличить удельную поверхность образца в 35 раз. Интенсивная механоактивация шунгита приводит к разрушению силикатного каркаса и высвобождению шунгитового углерода, связанного в агрегаты с кварцем. Образование большого количества несвязанного углерода, дефектных струк-

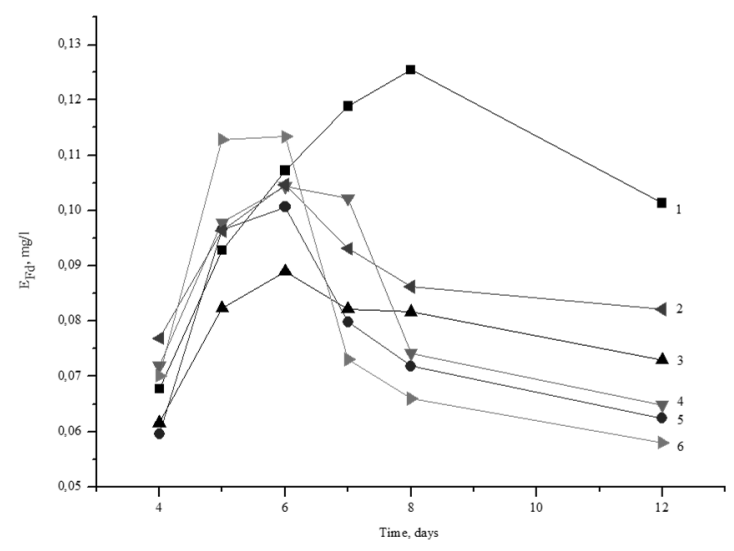

Рис. 5. Эмиссия формальдегида $\left(\mathrm{E}_{\mathrm{Fd}}, \mathrm{mg} / \mathrm{l}\right)$ из древесно-клееных материалов, содержащих в композитном клее адсорбционные наполнители: 1 - чистый клей

(без наполнителя); 2 - шунгит (размер частиц 40 мкм); 3 - ПМ-75; 4 - БАУ-7;

5 - сибунит; 6 - нанодиспергированный механоактивированный шунгит

Fig. 5. Formaldehyde emission $\left(\mathrm{E}_{\mathrm{Fd}}, \mathrm{mg} / \mathrm{l}\right)$ from wood-glued materials containing adsorption fillers in the composite adhesive: 1 - pure glue (no filler); 2 - schungite (particle size 40 microns); 3 - PM-75; 4 - BAU-7; 5 - Sibunit; 6 - nanodispersed mechanically activated schungite 
тур и активных центров приводит к повышению химической и адсорбционной активности шунгита.

Эмиссию формальдегида изучали на образцах фанеры, содержащих в клеевой композиции следующие адсорбционные наполнители: нанодиспергированный механоактивированный шунгит, активный уголь БАУ-7, Сибунит, углерод технический ПМ-75, а также на контрольном образце фанеры, склеенной чистым клеем. Как видно из рис. 5, увеличение эмиссии формальдегида в атмосферу происходит около 6 суток, затем наблюдается спад для образцов с адсорбционными наполнителями. Равновесие наступает через 2 недели. Для контрольного образца рост эмиссии наблюдается в течение 8 суток с последующим спадом.

Наиболее низкие значения выброса свободного формальдегида в атмосферу имеют образцы древесно-клееных материалов, содержащие в композитном клее нанодиспергированный механоактивированный шунгит и мелкодисперсный Сибунит. Содержание выделяемого в воздух формальдегида составляет при этом $0.040 \mathrm{Mг} / \mathrm{M}^{3}$, что в 2.5 раза ниже Европейской нормы 0.124 мг/ $\mathrm{M}^{3}$ формальдегида в воздухе[18].

\section{Заключение}

Показаны перспективы применения углеродсодержащих адсорбентов в качестве наполнителей клеевых композиций,

\section{Список литературы}

1. Цветков В.Е., Якунькин А.А. Технология и оборудование. Науч. тр. М.: МГУЛ, 2007. Вып. 338. С. 172-175.

2. Русаков Д.С., Варанкина Г.С., Чубинский А.Н. // Клеи, Герметики, Технологии. 2017. № 8. С. 16-20.

3. Чубинский А. Н., Варанкина Г. С. // Известия высших учебных заведений. Лесной журнал. 2013. № 6. С. 67-72.

4. Chubinsky A., Brutyan K. // Proceedings of Saint-Petersburg Forest Engineering Academy. 2009. Vol. 186. pp. 156-162. применяемых в конструкционных древесных материалах. Наиболее эффективными для снижения эмиссии формальдегида из древесно-клееных материалов являются образцы модифицированного механоактивацией шунгита и наноструктурированного углеродного материала Сибунит. Более конкурентно способным является шунгит, как дешевый, широко распространенный минерал. Технологически доступные способы модифицирования шунгита позволяют существенно развить его структурно-адсорбционные свойства. В результате модифицирования шунгита методами механоактивации и термоактивирования удалось увеличить его поверхность в 10-35 раз и получить образцы с высокой дисперсностью (в интервале от 90 нм до 40 мкм).

Показано, что в результате модифицирования в структуре шунгита происходят значительные фазовые изменения, связанные с разрушением силикатного каркаса и высвобождением углерода, связанного в агрегаты с кварцем. Установлено, что введение в клеевую композицию нанодиспергированного механоактивированного шунгита позволяет снизить эмиссию свободного формальдегида из древесных композитных материалов до $0.040 \mathrm{Mг} / \mathrm{M}^{3}$, что в два раза ниже нормы $0.124 \mathrm{мг} / \mathrm{m}^{3}$ формальдегида в воздухе.

5. Леонович А.А., Рабыш А.А. // Древесные плиты: теория и практика. 12-я Междунар. научно-практич. конф., 2009. № 10. С. 68-73.

6. Леонович А.А., Шелоумов А.Л. // Хuмия растительного сырья. 2010. № 2. С. 169176.

7. Варанкина Г.С., Чубинский А.Н., Брутян К.Г. // Клеи, Герметики, Технологии. 2017. № 6. C. 12-14.

8. Соловьева А,Б., Рожкова Н.Н., Глаголев Н.Н., Зайченко Н.Л., и др. // Журн. физ. химии. 1999. Т. 73. № 2. С. 299-305. 
9. Королев Ю.М., Колесников Б.Я., Ефремова С.В., Ефремов С.А. // Химия твердого топлива. 2000. № 2. С. 88-92.

10. Крылов И.О., Луговская И.Г., Петухова Г.А., Якушина О.А. // Тезисы II Международной конференции «Коллоид-2003». 2003. C.99.

11. Шалимов А.С., Ковалевский В.В., Обрезков О.Н., Ярославцев А.Б. // Неорганические материалы. 2004. Т. 40. С. 430-434.

12.Polunina I.A., Vysotskii V.V., Senchikhin I.N., Polunin K.E. et al. // Colloid J. 2017. No 2. pp. 244-249.

13. Dubinin M.M. // Carbon. 1989. Vol. 27. No 3. pp. 457-467.

14. Polyakov N., Dubinin M., Kataeva L.,
Petukhova G. // Pure Appl. Chem. 1990. Vol. 65 pp. 2189-2193

15. Поляков Н.С., Петухова Г.А. // Журнал российского химического общества им. Д.И. Менделеева. 1995. Т. 39. № 6. С. 7-14.

16. Кулькова Т.А., Аверин А.А., Клюев В.А., Буряк А.К. и др. // Материаль VII всероссийского симпозиума и Школь-конферениии молодых ученых «Кинетика и динамика обменных проиессов». 2018. С. 88-89.

17. Zatezky A. et al. // Carbon. 2005. Vol. 43. pp. 1731-1742.

18. EN 717-1-2005. Материалы древесные. Определение эмиссии формальдегида. Часть 1. Определение эмиссии формальдегида методом помещения в камеру.

\title{
Prospects for the use of shungite as a formaldehyde sorbent in composite materials
}

\author{
(C) 2021 Petukhova G.A., Kulkova T.A. \\ Frumkin Institute of Physical Chemistry and Electrochemistry, Russian Academy of Sciences of RAS, \\ Moscow, Russian Federation
}

\begin{abstract}
During the production of modern wood-based construction materials, synthetic adhesives are used, the toxicity of which is determined by the presence of free formaldehyde. The release of free formaldehyde from products can continue for an extended indefinite period. The development of methods for the reduction of the emission of formaldehyde during the production and the use of composite wood materials is undoubtedly an urgent task. The purpose of the study was the optimization of the method for increasing the adsorptionstructural characteristics of a filler based on natural schungite, the study of the effect of the porous structure of carbon-containing adsorbents used as fillers on the emission of formaldehyde in wood glued composite materials. Schungite, BAU-7 activated carbon, nanodispersed carbon material Sibunit and PM-75 soot were studied as fillers. For the development of a porous structure and an increase in the dispersion of schungite, the following methods of modifying schungite were used: dry mechanical activation, activation by electromagnetic fields in the range of $150 \div 800 \mathrm{~W}$ microwave (microwave EMF), steam-gas activation in various temperature and time modes and chemical activation with sulphuric acid. Chemical activation was carried out in a solution of $2 \mathrm{M}$ $\mathrm{H}_{2} \mathrm{SO}_{4}$ with constant stirring at a temperature of $97^{\circ} \mathrm{C}$ for 7.5 hours with a Heidolph LABOROTA 4000 rotary evaporator. The analysis of the texture and state of the surface of materials was carried out by equilibrium adsorption, vibrational spectroscopy, X-ray microanalysis (EDAX method). The emission of free formaldehyde was studied by the chamber method. It is shown that mechanical and thermal activation allowed increasing the schungite surface by a factor of 10-35 and obtain samples with high dispersion (in the range from 90 $\mathrm{nm}$ to $40 \mu \mathrm{m}$ ). The most effective as an adsorptive filler of the adhesive composition was the use of nanodispersed mechanically activated schungite and Sibunit. The use of nanodispersed mechanically activated schungite reduced the emission of formaldehyde from wood composite materials to $0.040 \mathrm{mg} / \mathrm{m}^{3}$, which is two times lower than the normal value $0.124 \mathrm{mg} / \mathrm{m}^{3}$ of formaldehyde in the air.
\end{abstract}

Keywords: carbon-containing sorbents, schungite, porous structure, adsorption, formaldehyde

\section{References}

1. TSvetkov V.E., YAkun'kin A.A. Tekhnologiya i oborudovanie. Nauch. tr., 2007, Vyp. 338, pp. 172-175.

2. Rusakov D.S., Varankina G.S., Chubinskij A.N., Klei, Germetiki, Tekh-nologii, 2017,
No 8, pp. 16-20.

3. CHubinskij A.N., Varankina G.S., Izvestiya vysshikh uchebnykh zavedenij. Lesnoj zhurnal, 2013, No 6, pp. 67-72.

4. Chubinsky A., Brutyan K., Proceed-ings 
of Saint-Petersburg Forest Engineering Academy, 2009, Vol. 186, pp. 156-162.

5. Leonovich A.A., Rabysh A.A., Drevesnye plity: teoriya i praktika. 12-ya Mezhdunar. nauchno-praktich. konf., 2009, No 10, pp. 68-73.

6. Leonovich A.A., SHeloumov A.L., Khimiya rastitel'nogo syr'ya, 2010, No 2, pp. 169-176.

7. Varankina G.S., CHubinskij A.N., Brutyan K.G., Klei, Germetiki, Tekhnologii, 2017, No 6, pp. 12-14.

8. Solov'eva A,B., Rozhkova N.N., Glagolev N.N., Zajchenko N.L. et al., Zhurn. fiz. khimii. 1999, Vol. 73, No 2, pp. 299-305.

9. Korolev Yu.M., Kolesnikov B.YA., Efremova S.V., Efremov S.A., Khimiya tverdogo topliva, 2000, No 2, pp. 88-92.

10. Krylov I.O., Lugovskaya I.G., Petukhova G.A., Yakushina O.A., Tezisy II Mezhdunarodnoj konferentsii «Kolloid-2003», 2003, pp. 99.

11. Shalimov A.S., Kovalevskij V.V., Obrezkov O.N., Yaroslavtsev A.B., Neorganicheskie

Петухова Галина Анатольевна - к.х.н., заведующая лабораторией синтеза и исследования сорбентов ИФХЭ РАН, Москва

Кулькова Татьяна Алексеевна - н.с., ИФХЭ РАН, Москва materialy, 2004, Vol. 40, pp. 430-434.

12. Polunina I.A., Vysotskii V.V., Senchikhin I.N., Polunin K.E. et al., Colloid J., 2017, No 2, pp. 244-249.

13. Dubinin M.M., Carbon, 1989, Vol. 27, No 3, pp. 457-467.

14. Polyakov N., Dubinin M., Kataeva L., Petukhova G., Pure Appl. Chem., 1990, Vol. 65, pp. 2189-2193

15. Polyakov N.S., Petukhova G.A., Zhurnal rossijskogo khimicheskogo obshchestva im. D.I. Mendeleeva, 1995, Vol. 39, No 6, pp. 7-14.

16. Kul'kova T.A., Averin A.A., Klyuev V.A., Buryak A.K. et al., Materialy VII vserossijskogo simpoziuma $i$ SHkoly-konferentsii molodykh uchenykh "Kinetika $i$ dinamika obmennykh protsessov», 2018, pp. 88-89.

17. Zatezky A. et al., Carbon, 2005, Vol. 43, pp. 1731-1742.

18. EN 717-1-2005. Materialy dreves-nye. Opredelenie emissii formal'degi-da. CHast' 1. Opredelenie emissii for-mal'degida metodom pomeshcheniya $\mathrm{v}$ kameru.

Petukhova Galina A. - Ph.D. (Chemistry), Head of Sorbent Synthesis and Research Laboratory of IPCE RAS, Moscow

Kulkova Tatiana A. - Researcher, IPCE RAS, Moscow 